\title{
Extending Tangible Interactive Interfaces for Education: A System for Learning Arabic Braille using an Interactive Braille Keypad
}

\author{
Hind Taleb Bintaleb ${ }^{1}$, Duaa Al Saeed ${ }^{2}$ \\ Information Technology Department, College of Computer and Information Sciences \\ King Saud University, Riyadh, KSA
}

\begin{abstract}
Learning Braille for visual impairments means being able to read, write and communicate with others. There exist several educational tools for learning Braille. Unfortunately, for Arabic Braille, there is a lack of interactive educational tools and what is mostly used is the traditional learning tools, such as the Braille block. Replacing those tools with some more effective and interactive e-learning tools would help to improve the learning process. This paper introduces a new educational system with a tangible and interactive interface. This system aims to help blind children to learn Arabic Braille letters and numbers using an interactive tactile Braille keypad together with the educational website. The interactive tactile Braille keypad was built using an Arduino connected with the educational website. A usability test was conducted and results showed that the system is easy to use and suggested that using the interactive Braille keypad with the educational website will improve the learning outcomes for blind children.
\end{abstract}

Keywords-Braille; tangible interface; e-learning; Arduino; accessibility; usability; visually impaired; blind

\section{INTRODUCTION}

In our life, literacy which is the ability to read and write is substantial in different aspects such: education and communication. It helps one to lead their own life without depending on others. Learning to read and write is considered an important step especially in at childhood. It is important to gain basic knowledge about the language and enhance skills in reading and writing.

People who are blind or have low vision need to practice their lives normally. They have the right to learn everything such: reading and writing. The Braille system helps them to understand and to study non-visual modes of communication.

Braille is a tactile system for reading and writing used by blind people or those who have poor vision. Braille was named after its inventor Louis Braille $(1809$ - 1852) who was blind. In 1824, at age 15 Braille presented this system to help blindness and people with poor vision in reading and writing quickly and more easily. Braille is not a language, but it is a representation of any language character using 6 dots ordered in a matrix of 2 x 3 "two columns with three rows", see Fig. 2. A certain set of dots when raised represent a certain character, sixty-four combinations are possible using one or more of these six dots [1].
A basic Braille template (cell) is a tactile configuration of six raisedlembossed dots. It is upright rectangular shapes made of two vertical columns made of three dot positions. The cell is organized as a matrix of $2 \times 3$ dots. Those dots are numerically identified by the numbers 1 to 6 , see Fig. 2 . There are different combinations of raisedlembossed dots, each unique configuration represents an alphabetical letter or a number or a symbol. a consonant, a vowel, a number, a diacritical mark or an abbreviated suffix [2][3]. Through the combination of dot positions and their distribution on the two vertical columns, the symbol takes a distinctive tactile shape. Empty dot positions help the reader identify the embossed positions forming the letters. Between dot cells there is a barrier. The direction of embossing symbols is right to left, and reading goes from left to right, even in Arabic and in topto-bottom scripts [3].

Learning Braille is challenging, it takes time and practice. It needs the support and encouragement of family and teachers; thus, it is important to provide students, their families and teachers with digital tools that could enhance this process and make it easy and fun. There are several educational tools for learning English Braille. Unfortunately, for Arabic Braille, we still use the old traditional learning tools, such as the Braille block, see Fig. 2. Replacing those tools with some more effective and interactive tools would help to improve the learning process. Thus, in this study present an Arabic Braille learning system with an interactive tactile Braille keypad.

The paper is structured as follows: Section 2 shows the related work. A description of software accessibility will be presented in Section 3. In Section 4, we will present our developed Arabic Braille educational system. Section 5 covers system and usability testing. We conclude with Section 6 where we discuss conclusions and future work.

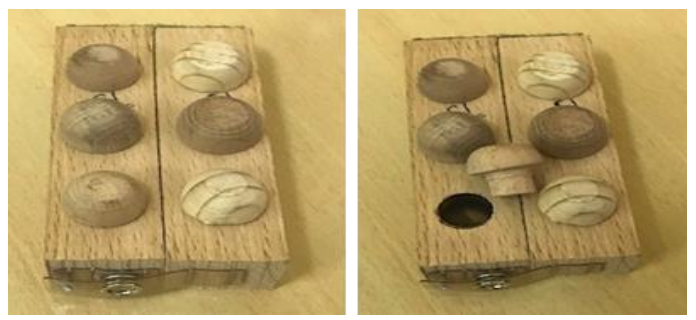

Fig. 1. Traditional Braille Alphabetic Learning Tool [4]. 


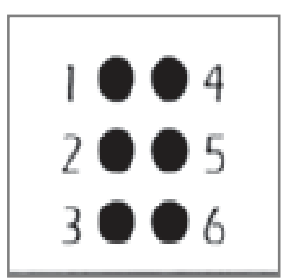

Fig. 2. The Structure of the Basic Braille Cell [2].

\section{RELATED WORK}

Learning Braille is very important for the blind and people with low vision to be able to read and write.

Many studies have been conducted presenting different solutions to enhance the process of learning Braille. In our review of literature, we found that some of the research studies focuses on presenting a Braille learning system using self-contained hardware. One of the most recent studies [19] conducted a BraillePad to help the children learning English and Tagalog Braille, another study [20] is proposed to learn Spanish Braille for visually impaired users. In [5] they used US English QWERTY keyboard with 6 solenoids and microcontroller and an alphabet input will be entered by a non-visually impaired person to help the visually impaired user in learning the Arabic Braille character.

On the other hand, other studies presented systems with assistive integrated hardware together with an educational software for learning Braille. Various studies have conducted an incorporate environment of hardware and software to help in Braille learning process. One of the most recent studies in this domain is [6] which introduced an innovative system to learn Taiwanese Braille using Braille learning gloves. Similar to the previous study in [7] built a Vibrotactile BrailleReading Device called UbiBraille. It is inspired by the standard writing system of the Perkins Brailler. In [8] study the (OBR) system was designed. It is an innovative use of RFID and developing new uses for RFID technologies. The OntoBraille@RFID (OBR) it is a Braille learning platform consisting of identified RFID tags, RFID reader and the learning software.

Generally, each of study provides a set of different hardware combination and innovative for Braille learning. Table I summarizes the studies and shows additional information about the used technologies. . It can be clearly seen, that only two out of the four studies developed systems supporting two languages for support Braille system, while the remaining supported only one language. None of these systems is supporting the Arabic Braille. Not all systems proposed in those studies are providing three levels of learning (i.e. character, word and sentence), four out of six have covered learning characters and words, and one, system covered only characters. One study has presented a system that covers all three levels and it supported Chinese and English languages for Braille system.

As far as we know, no studies available have proposed or developed a Braille learning system (hardware integrated with software) in Arabic language. Thus, in this study aims to presenting an Arabic Braille learning system consisting of both hardware and software components. It integrates a specially designed Braille interactive keypad with Arduino technology, together with a web-application for learning Arabic Braille (numbers and characters) which none of the previous systems have provided.

\section{SOFTWARE ACCESSIBILITY}

Accessibility is a term which have a range of definitions. It describes how is it easy to use E-Systems by people with special needs [9]. It means to remove any barriers that face people with special needs from performing life activities and other services [10]. Any software should be accessible by normal users and those with special needs. Software accessibility is extremely important and will always be quite challenging for software designers, they need to ensure that people with disabilities can get full access to a system so they can interact, navigate, perceive, and understand it [11]. In order to achieve accessibility, software designers and developers take into consideration the fact that the ability to see, hear, interact with the system, read text or process information varies from user to user. In fact, some users require special assistive input and output technologies to help them carry out these activities. Several key legal issues, accessibility guidelines, and resources are available to help in making software accessible to individuals with disabilities. Here we try to summaries some of the main issues to be considered, when designing a software, to improve the accessibility for the visually impaired [12][9]:

- Text must be resizable and high color contrast is important. The visual information should be represented in a descriptive text associated with images and other multimedia and vice versa[12][12][12][12] [12][12][12].

- All visual content must be supported with an alternative auditory and readable content. In the case of images, this mean adding an alt attribute to describe its content.

- The language of the page contents should be declared with markup to facilitate the pronunciation for screen readers.

- User interface should follow principles of accessible design, such as: device-independent access to functionality, keyboard operability, self-voicing.

- Enabling the feature of multimodality of input such: keyboard, speech, mouse or other pointing device.

- Grouping elements and providing contextual information about the relationships between elements can facilitate access to those elements.

- Documents should be clear and simple and easily understood.

\section{DEVEloped BRAILle EduCATIONAL SySETM}

In this section we present our design process and discuss system architecture, hardware and software system components. 


\section{A. System Architecture}

The architecture of the proposed system is a Client-Server architect. The rationale behind this design decision is as follows:

- The data on a remote server can be accessed by any device (PCs, mobiles, tablets and laptops) via the internet.

- No need for installation on the user device.

- Web-based systems are supported by NVDA screen reader in contrast to a built-in PC program.

- Web-based systems support the accessibility standards and every element can be accessed by the keyboard commands such: tabindex, alt and access key properties, whereas the PC programs are not.

- Web-based systems can be converted to the mobile view so, the users can open the sites by their mobiles easily and efficiently. Fig. 3.

An illustration of the system architecture is presented in

\section{B. Database Architecture}

MySQL BD has been used to store all the letters, numbers, sounds and images. Database is used instead of files or arrays cause the large data we have. Storing data in a DB is more manageable than storing in files or arrays. ER of the system is illustrated in Fig. 4.

TABLE. I. RELATED BRAILLE LEANING SYSTEMS SUMMARY

\begin{tabular}{|c|c|c|c|c|}
\hline Ref & $\begin{array}{l}\text { Braille } \\
\text { Language }\end{array}$ & $\begin{array}{l}\text { Learning } \\
\text { Level }\end{array}$ & $\begin{array}{l}\text { Assistive } \\
\text { Technique } \\
\text { Type }\end{array}$ & Technology \\
\hline [13] & $\begin{array}{l}\text { English and } \\
\text { Tagalog }\end{array}$ & $\begin{array}{l}\text { characters } \\
\text { and words }\end{array}$ & $\begin{array}{l}\text { Auditory } \\
\text { feeding }\end{array}$ & $\begin{array}{l}\text { Arduino Mega and } \\
\text { LCD screen }\end{array}$ \\
\hline [6] & Taiwanese & $\begin{array}{l}\text { characters } \\
\text { and words }\end{array}$ & $\begin{array}{l}\text { Auditory } \\
\text { feeding and } \\
\text { vibrotactile } \\
\text { capabilities. }\end{array}$ & $\begin{array}{l}\text { a small-sized } \\
\text { microcontroller } \\
\text { (MTK7697) with } \\
\text { built-in Bluetooth } \\
\text { and battery } \\
\text { module }\end{array}$ \\
\hline [14] & Spanish & $\begin{array}{l}\text { characters } \\
\text { and words }\end{array}$ & $\begin{array}{l}\text { Auditory } \\
\text { feeding and } \\
\text { tactile } \\
\text { material }\end{array}$ & $\begin{array}{l}\text { Portable device } \\
\text { with Bluetooth } \\
\text { adopted in, and } \\
\text { USB inputs }\end{array}$ \\
\hline [5] & Arabic & characters & $\begin{array}{l}\text { Tactile } \\
\text { material }\end{array}$ & $\begin{array}{l}\text { Microcontroller } \\
\text { PIC16F877A, } \\
\text { LCD display }\end{array}$ \\
\hline [7] & English & $\begin{array}{l}\text { characters } \\
\text { and words }\end{array}$ & $\begin{array}{l}\text { vibrotactile } \\
\text { capabilities }\end{array}$ & $\begin{array}{l}\text { Arduino Mega } \\
\text { ADK board, } \\
\text { vibration motor }\end{array}$ \\
\hline [8] & $\begin{array}{l}\text { Chinese and } \\
\text { English }\end{array}$ & $\begin{array}{l}\text { Characters, } \\
\text { words and } \\
\text { sentences }\end{array}$ & $\begin{array}{l}\text { Auditory } \\
\text { feeding using } \\
\text { MS Speech } \\
\text { and tactile } \\
\text { material }\end{array}$ & RFID \\
\hline
\end{tabular}

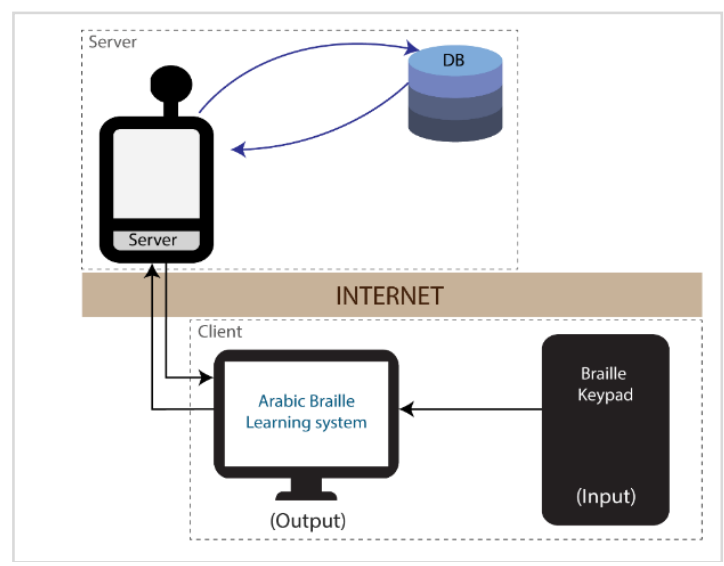

Fig. 3. The System Architecture.

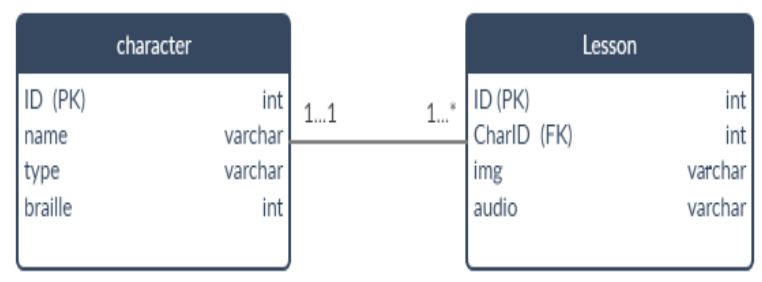

Fig. 4. Entity Relation Diagram.

\section{Interactive Braille Keypad}

It is an input Braille keypad device designed to implement the traditional Braille block to be used to navigate throughout the system and interact with it.

It has eight buttons: six for the Braille dots representation, an Enter button and a Tap button to navigate through the system elements. It is the main input device in the system. The Braille keypad device has two parts, first part consists of six numbered buttons dots forming two columns, three buttons each. Second part consists of two buttons for Enter and Tap commands. Fig. 5 illustrates the Braille keypad sketch. The keypad was designed to be more accessible and easier to use one hand.

\section{Hardware}

Mini Arduino Leonardo was used to control the keyboard commands. Arduino controller will be integrated inside the keypad. It consists of the following:

- Mini Arduino Leonardo

- Buttons (2 pieces)

- Toggle-switches (6 pieces)

- USB connector

- Other connectors

Arduino Leonardo: according to the official Arduino web site: "Arduino is easy to use hardware and software electronic platform, which is an open source" [15]. Arduino has many different versions and types, Arduino Leonardo Fig. 6 was used because it has a built-in USB communication and it controls the keyboard commands. 


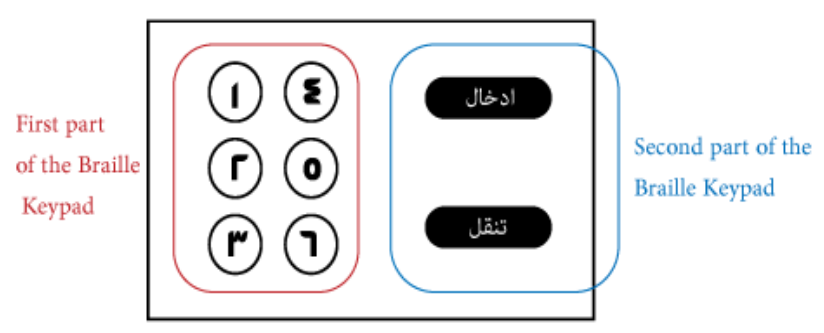

Fig. 5. Braille Keypad Sketch.

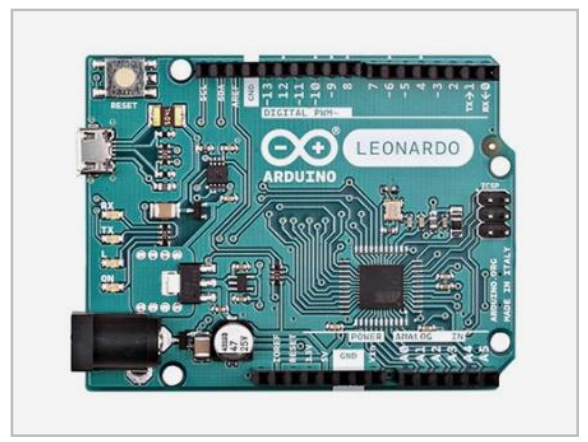

Fig. 6. Arduino Leonardo[15].

Breadboard: a breadboard is a widely used tool for designing and testing circuit [16] as shown in Fig. 7. For this project, the breadboard will be used to connect the ground (GND) pin from Arduino to its row.

Jumper cable: cable will be used to connect Arduino with sensors and relay. Latching push button switch: this button acts as Off/On maintained switch. We have chosen this button with a flashed light when pressed to provide more accessibility for visual impairments users. Button: normal button Off/On.

\section{E. Educational Website}

In order to provide an effective learning system, we had to understand the problem space, learn about Braille system and get more insight in order to be able to gain a better understanding of the system's requirements which basically targets the visual impaired children. For that, we visited AlNour Institute for the blind. During this visit, we conducted interviews with elementary school teachers teaching the three foundation courses. These courses teach the basis of Arabic Braille for students in their first study year. The main purpose of these interviews was to learn about the teaching strategies, in addition to getting their suggestions and recommendations on teaching Braille.
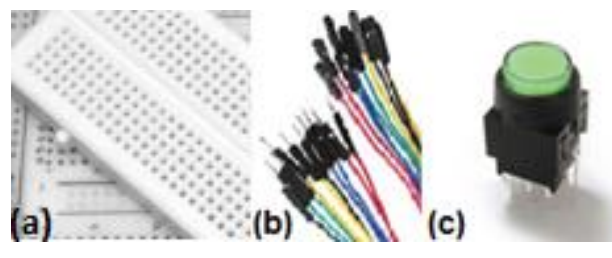

(d)

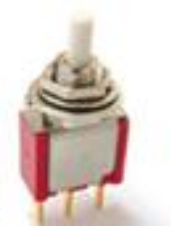

Fig. 7. Images of Some of the Hardware Parts used in Designing the Interactive Keypad : (a) Breadboard, (b) Jumper Caples (c) Latching Push Button Switch (d) Button [16].
Based on a well-established set of requirements, the educational website was designed to consist of 5 sub-modules:

a) About Braille cell: this module is an introductory lesson about the Braille cell providing an audible explanation of the structure and coding of Braille cell.

b) How to use the Braille Keypad: before going into learning Braille, learner needs to be introduced to the main interface of the system which is the speciallly design keypad to simulate a Braille cell and interact with the system. The system provides the learner, while sensing the keypad, with an audible explanation of the shape and structure of the keypad and how to use it, this includes the different buttons and the action of each.

c) Arabic Braille learning: This is the core module of the system with the main functions. The main user interface of the learning module includes three main functions:

- Lesson: the explanation lesson of the Arabic Braille character (letter or number).

- Practice: a practicing option that enables the child to try and write the character with Braille keypad without any constraints such as times or score.

- Re-learn: this is an option which gives the child the choice of replaying the lesson.

First, the learner should choose the letter/number lesson either by selecting a letter/number from the list or continue from the lesson he stopped on. The lesson will start showing a word that starts with the letter to be learned and saying the word and the letter, e.g. the word "أسد" starts with the letter "l)", the letter will be represented on screen by the Braille cell and will be explained using texts, images and audio materials. The same thing for numbers' lessons, e.g. three flowers will appear with the number " 3 ". It will be represented on screen by the Braille cell and will be explained. After finishing the lesson, the practicing mode will appear to make sure that the learner has been understood the lesson or he/she can repeat the lesson again. In practice, the system will show and pronounce the letter/number. Then, the learner will be asked to answer using the Braille keypad. If the answer is correct, the system will ask the learner either to go to the next lesson or go back to the previous page. Else the learner has the choice to re-answer again or chooses re-learn option to repeat the lesson from the beginning. An illustration of this scenario is shown in Fig. 8.

d) Testing: an important part in any eduacational system is knowlwdge testing. In this module, the testing mechanism for letters and numbers is the same, where ten random letters or numbers will be chosen; depending on the selected learning (letters or numbers). The system will ask the learner to enter the matched Braille code of the displayed character using the Braille keypad as it is illustrated in Fig. 9. The learner has three attempts for incorrect answers, after the third incorrect answer, the system will show him the correct answer. Finally, total scores with the feedback will be displayed after finishing the test. 


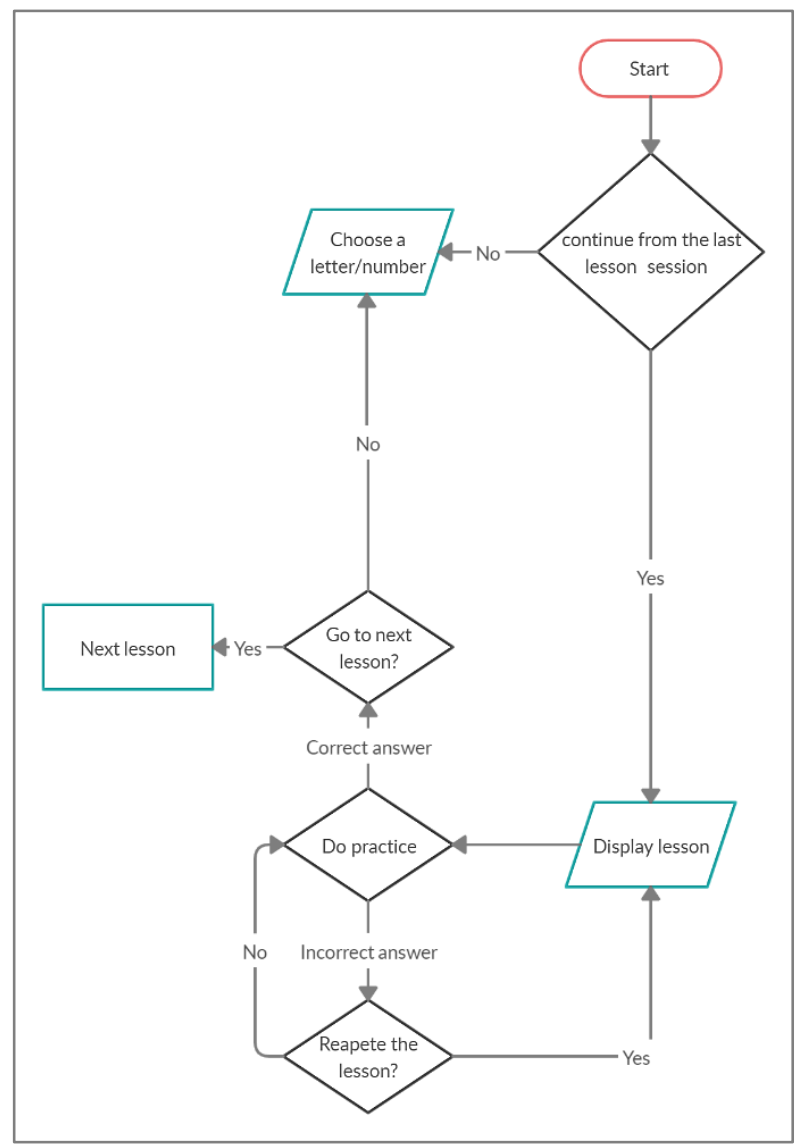

Fig. 8. Flow Chart of the Lesson.

اسسوال 10

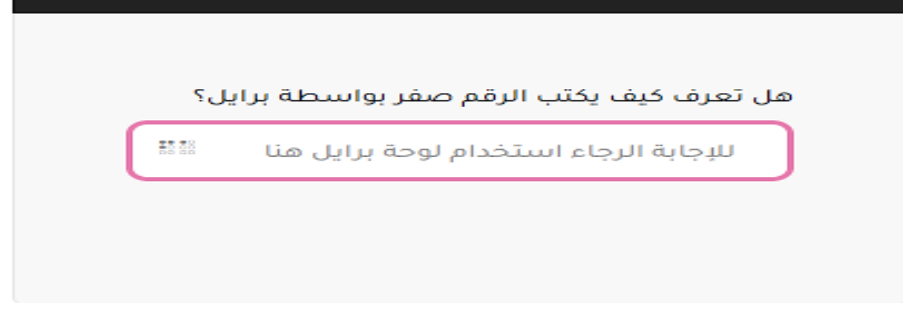

Fig. 9. A Testing Example (Testing Number 0).

e) Reporting: providing a progress repor is very usefull for the parents/teachers to monitor and guide the learner during the learning process. Once the learner exits from the system a complete readable report will show the progress, lessons history, practice and test results with the feedback. Those reports are compatible with screen readers.

\section{System AND Usability TestingS}

We conducted two separate evaluations for the developed system. First a system testing was conducted to ensure that the system meets its functional and nonfunctional requirements. The main objective of is to evaluate the sufficiency of functionality. This includes: unit testing, system testing, and quality testing.
Usability and accessibility tests are very important especially when developing a system for users with special needs. Thus, the second evaluation is a usability test conducted with blind children, and the accessibility test was performed as part of system testing. In the following subsections we discuss all tests performed, starting with unit testing followed by system testing and quality testing. We conclude with the usability test.

\section{A. Unit Testing}

Unit testing is verifying a particular component of the system and checking if it is working without any errors [17]. It tests a unit of the system individually, so it verifies that a specific piece of code performs as expected. Unit testing of the system functions was passed successfully.

\section{B. System Testing}

System testing is the testing to evaluate the whole web application's compliance with specified requirements such: number of broken links/URLs in the site, web accessibility standards and the compatibility with most used browsers [18]. In order to test our website, we used an automatic evaluation tool named SortSite [19]. The tool was released in 2007 and widely used by many since then.

a) Links/URL Testing: the tool shows that the website has no missing images or broken links see Fig. 10.

b) Web Accessibility Testing: we test the website to ensure that it complies with accessibility best practice guidelines that make the web application accessible to people with disabilities. As a result, the website meets WCAG 2.0 [20] Level A conformance and Level AA with two issues.

c) Browser Compatibility Testing: the tool shows that the website is compatible with the major browsers, i.e. Internet Edge, Firefox, Safari, Opera, Chrome, and mobile browsers. However, users using old versions of Safari might face minor issue that will not prevent them to benefit from the website.

\section{System Quality Testing}

We evaluate the system to test whether our system meets the specified non-functional requirements. We used SQuORE analytics tool to perform the quality testing. SQuORE is an intelligence tool that has been founded in 2010 by a group of software engineering experts. SQuORE supports a lot of different programming languages so, it has the ability to assess a project that has been developed under multi-languages. This tool has a friendly interface that can be easily deal with it and understand the analysis result [21].

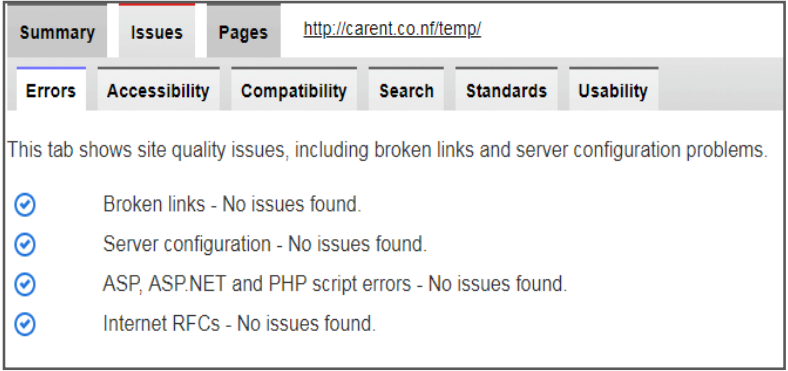

Fig. 10. SortSite Results - Links/URL Testing. 
"SQuORE business intelligence tool introduces a novel decision-based approach to software projects quality assessment by providing a more reliable, more intuitive, and more context-aware view on quality [22]." There are huge of software quality measurements such: cyclomatic complexity for control flow, Comment Density, etc. In SQuORE tool proposes several models and standards such: ISO 9126 and the Automotive HIS [22]. HIS (Hersteller Initiative Software) specifies a fundamental set of Metrics to be used in the evaluation of software and quality assessment. Each of these defined metrics is studied and reported. All violations of the agreed boundary limits at the function level have to be justified [23]. The results show that all the specified strategies are within the range. Moreover, the fault tolerance has the highest value that may affect the system reliability. The lowest page quality is the test page which has an "E" key performance whereas five pages of " $D$ " key performance and three pages of " $\mathrm{A}$ " key performance which is the highest quality indicator.

\section{Usability Testing}

We conducted a usability study to determine how usable, satisfactory, efficient, and effective the web site is for the users, identify any usability problems and finding ways of improving the usability of the system. A total of three blind children participated in this study. To demonstrate this study, this testing is divided into the following: 1) test environment set-up. 2) participants. 3) evaluation methods of. 4) assessment measures. 5) tools 6) results. 7) findings and recommendations.

a) Enviroment setup: the evaluation was conducted in a quiet and closed meeting room at Kafeef Organization. Our laptop as a local host for our system is placed on a meeting desk. The visually impaired child is setting on a chair facing the laptop while his hand is on the Braille keypad. The child mother was present in the room during the evaluation for assistance. Fig. 11 shows the environment set-up with a visually impaired child.

b) Participants: a sample of three children were recruited in the study as shown in Table II. Two participants were male and one female. All were (4-9) aged. 2 out of 3 were totally blind and only one was partial visually impaired. Moreover, none of them has advanced background of the Arabic Braille letters and numbers. In addition, none of the participants is familiar with a screen reader or have been used educational sites or have used technology and Internet before except for participant (P2) who used to access Internet and educational site using iPad. All participants looking to use an Arabic Braille learning system and think that it will help them to learn.

This study was approved by association of the blind (Kafeef) Ethics Committee. Parents of the participants were informed that the test outcomes will be used for research purposes only and were assured that privacy and personal identity information of all participants will be protected.

c) Methods: two of the industry-standard usability methods were applied in this evaluation: subject evaluation via pre-test and post-test interviews and the observation method during the testing session [24].

Once the parents of the children participants accept and sign the consent form. A pre-test interview questions are conducted. The goal of the pre-test interview is to gather children's demographic information such as gender and age, their background of Arabic Braille, technical experience such as using the Internet and educational web sites. During the test session, we have selected the observation usability evaluation method to watch the participants while they are using the system and take notes. Participants were asked to complete several tasks in the system. These tasks include:

- Task 1: Choose the Arabic letters learning option.

- Task 2: Go to the "ب" lesson.

- Task 3: Perform practice of the chosen lesson and answer the question.

- Task 4: Trying to go to the Arabic letters' test and answer the first question using the Braille keypad.

- Task 5: Trying to exit the program and see the report of current session.

TABLE. II. PRE-TEST INTERVIEW COLLECTED INFORMATION

\begin{tabular}{|l|l|l|l|}
\hline Participant No. & P1 & P2 & P3 \\
\hline Gender & Male & Male & Female \\
\hline Age & 4 & 9 & 8 \\
\hline Visually impaired kind & $\begin{array}{l}\text { Total } \\
\text { (Blind) }\end{array}$ & Partially & $\begin{array}{l}\text { Total } \\
\text { (Blind) }\end{array}$ \\
\hline Arabic Braille background & No & Junior & junior \\
\hline Familiar with Screen reader & No & No & No \\
\hline Educational sites used before & No & Yes & No \\
\hline Technology and Internet usage & Not using & $\begin{array}{l}\text { Using iPad } \\
\text { weakly }\end{array}$ & Not using \\
\hline $\begin{array}{l}\text { looking to use an Arabic } \\
\text { Braille learning system }\end{array}$ & Yes & Yes & Yes \\
\hline $\begin{array}{l}\text { If there is an educational site } \\
\text { for Arab Braille, do you think } \\
\text { that it will help you to learn }\end{array}$ & Yes & Yes & Yes \\
\hline $\begin{array}{l}\text { Would like to use educational } \\
\text { sites for the visually impaired }\end{array}$ & Yes & Yes & Yes \\
\hline
\end{tabular}

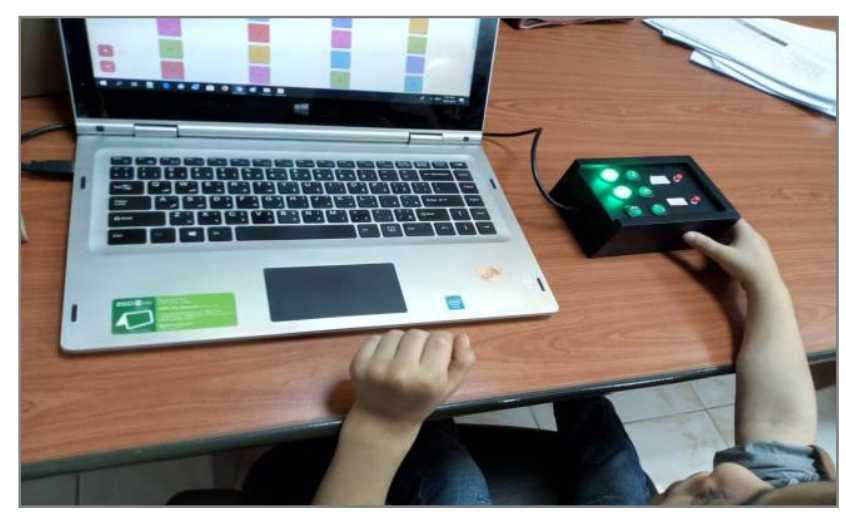

Fig. 11. The Environment Set-up with a Visually Impaired Child. 
Once the participants complete the tasks, they interviewed with help of their mothers to get their overall impression of the system after using it. Most of the questions contained a Likert scale to assess the user experience of the system, satisfaction level of the system and if issues were countered. Moreover, we asked questions about whether the children would like to use the web site in the future and if they have any recommendations to enhance the web site or the Braille keypad.

d) Assesment Measures: In order to measure the usability of our system, we concerned in conducting the usability test in terms of efficiency, effectiveness and satisfaction. Table III describes each term and its measurement data.

e) Tools: Two software tools were used to assist the completion of this evaluation. These tools are:

- Morae: a usability software tool that allows recording the user's interactions on the screen. The software was installed on the laptop, which allows us to have a portable usability lab [25].

- Excel: was used to analyze the observed data and draw charts.

f) Results: All the participants completed the given tasks successfully, except one participant (P1) who could not complete Tasks 2 and 4. From our observation, we found that this participant doesn't know what laptop means or even website and he doesn't know any Arabic letters or numbers. He may need extra preparation sessions to introduce him to the technology and to be familiar with it before performing the test. We calculated the efficiency of the web site by measuring the task completion time see Table IV. The participants were varying in the time spent to complete these tasks. Fig. 12 shows the time spent on each task in seconds for each participant. It reveals that the best result was achieved by the participant (P2) who spent the shortest time in all tasks compared to the other participants. His progress performance was due to the fact that he used to use the technology in addition to his experience in using educational sites. Moreover, we can notice that as demonstrated in Fig. 13 Task 4 took the longest time. We think that this is due to its order of other tasks, it needs to go back twice from the previous task page to achieve it.

Other performance metrics to measure is the effectiveness of the system which was calculated by the number of user errors and number of assistances required to complete each task. Regard the number of user errors for each task only participant (P1) commit an error in two tasks (Task 2 and 4). In fact, the same error was because the participant entered the url link settings by mistake and ended the task. However, Task 2 needed the greatest number of assistances to complete than other tasks by average of $56 \%$. all the children found the system is motivative and have enjoyed the learning by the web site. Moreover, they agreed that the Braille keypad was easy. Two of them stated that the web site was easy to use, and they felt successful but with tired, and we think that feeling "tired" maybe due to the new experience and being anxious to do it successfully. Additionally, children were asked to give their suggestions and recommendations to improve the system. Most of them gave the same suggestion, which is disable the url to be unreadable by the screen reader.

g) Findings and recommendations: the recommendations we get are driven by the participant behaviors, verbal feedbacks, comments and suggestions that we ask participants after using the system. These recommendations are either for the web site or for the Braille keypad and range from highly important to less important, depend on the number of users that recommend or faced the same issues. The following TABLE I summarizes the recommendations.

TABLE. III. The MEASUREMENT DATA FOR THE UsABILITY TESTING

\begin{tabular}{|l|l|l|}
\hline & Metrics & Measurement \\
\hline \multirow{2}{*}{$\begin{array}{l}\text { Quantitative } \\
\text { measures }\end{array}$} & Efficiency & -Task Completion Time \\
\cline { 2 - 3 } & Effectiveness & $\begin{array}{l}\text {-Number of user errors } \\
\text {-Number of assistances required } \\
\text { to complete each task }\end{array}$ \\
\hline $\begin{array}{l}\text { Qualitative } \\
\text { measures }\end{array}$ & Satisfaction & $\begin{array}{l}\text {-Participant's opinion and their } \\
\text { satisfaction of the system }\end{array}$ \\
\hline
\end{tabular}

TABLE. IV. PERformance Results

\begin{tabular}{|l|l|l|l|l|l|}
\hline User & Task 1 & Task 2 & Task 3 & Task 4 & Task 5 \\
\hline P 1 & 46.00 & 112.00 & 30.00 & 323.00 & 38.00 \\
\hline P 2 & 19.00 & 22.00 & 12.00 & 27.00 & 10.00 \\
\hline P 3 & 33.00 & 51.00 & 18.00 & 65.00 & 18.00 \\
\hline Average & 32.67 & 61.67 & 20.00 & 138.33 & 22.00 \\
\hline
\end{tabular}

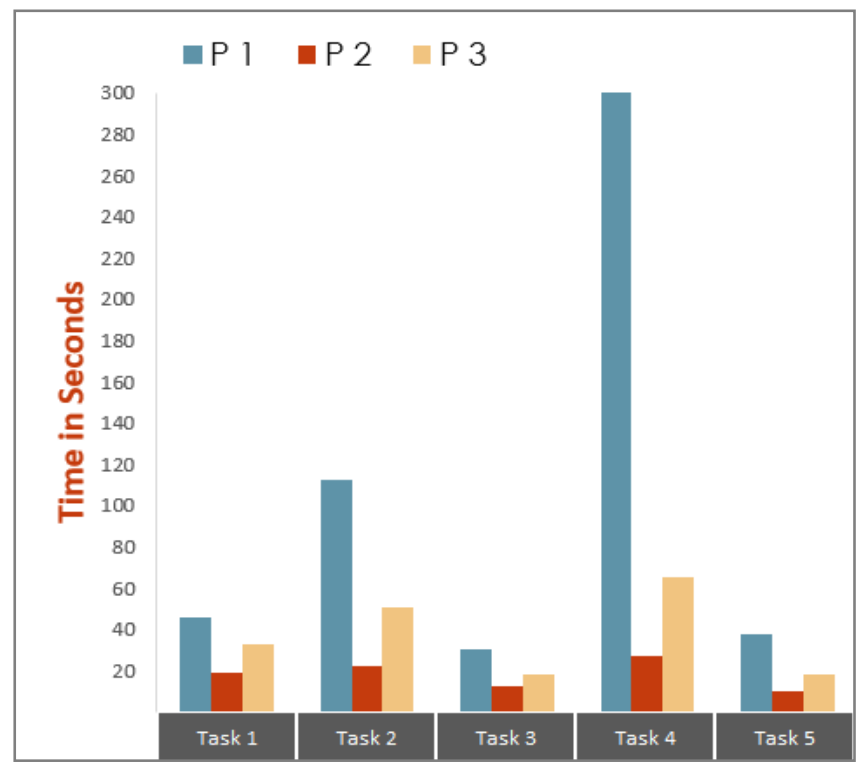

Fig. 12. Time Spent on Each Task by Seconds. 


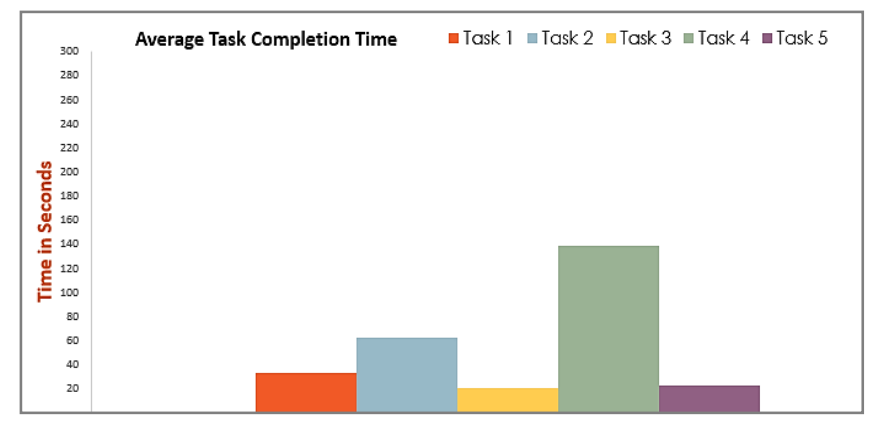

Fig. 13. Average Task Completion Time.

TABLE. V. TABLE I. FINDING AND RECOMMENDATIONS

\begin{tabular}{|c|c|c|c|}
\hline \# & Recommendation and Suggestions & Location & Priority \\
\hline 1 & $\begin{array}{l}\text { The URL of the page should be disabled } \\
\text { or not readable by the screen reader } \\
\text { because it interrupts the movements } \\
\text { between site elements. Moreover, its in } \\
\text { English languages so its not } \\
\text { understandable by users. }\end{array}$ & website & High \\
\hline 2 & $\begin{array}{l}\text { The user should practice many times to be } \\
\text { familiar with the screen reader and learn } \\
\text { himself without any intervention from his } \\
\text { parents }\end{array}$ & website & High \\
\hline 3 & $\begin{array}{l}\text { Should control the buttons lighting in the } \\
\text { Braille keypad because this is annoying } \\
\text { for visually impaired users. on other hand, } \\
\text { some visually impaired found that the } \\
\text { high light helps them to place the Braille } \\
\text { dots. }\end{array}$ & $\begin{array}{l}\text { Braille } \\
\text { Keypad }\end{array}$ & High \\
\hline 4 & $\begin{array}{l}\text { Providing a button to repeat what the } \\
\text { screen reader said instead of going } \\
\text { through elements again }\end{array}$ & website & Moderate \\
\hline 5 & $\begin{array}{l}\text { Providing a choice to change the buttons } \\
\text { color }\end{array}$ & $\begin{array}{l}\text { Braille } \\
\text { Keypad }\end{array}$ & Low \\
\hline 6 & $\begin{array}{l}\text { Putting two Braille cells instead of one } \\
\text { which make it more feasible in learning } \\
\text { the Arabic numbers }\end{array}$ & $\begin{array}{l}\text { Braille } \\
\text { Keypad }\end{array}$ & Low \\
\hline 7 & $\begin{array}{l}\text { Provide a chargeable Braille keypad that } \\
\text { connected wireless with any portable } \\
\text { device }\end{array}$ & $\begin{array}{l}\text { Braille } \\
\text { Keypad }\end{array}$ & Low \\
\hline
\end{tabular}

\section{FUTURE WORK}

Future work efforts will focus on adding new features and higher level lessons such as including diacritics marks and Arabic words. We also plan to implement the recommendations concluded from the results of usability testing. We hope to enhance this system by improving the designed keypad and incorporate more than one cell to be able to spell words not only code letters and numbers.

\section{VII.CONCLUSION}

The proposed system facilitates the Braille learning process. It is designed to help the blind and visually impaired in learning Arabic Braille (letters and numbers) using a specially designed interactive tactile Braille keypad. The proposed system is not limited to the blind or visually impaired, but it can also be used by sighted people to learn Braille which is important in families having visually impaired children. A usability test was conducted and results showed improvements in the learning process and the use of interactive tactile Braille keypad was highly accepted by blind children who participated in the test. We hope that this work will be a valuable contribution to our community and especially to the visually impaired.

\section{ACKNOWLEDGMENT}

Authors would like to thank Al-Nour Institute for the Blinds for their support and cooperation in this study. This research project was supported by a grant from the "Research Center of the Female Scientific and Medical Colleges", Deanship of Scientific Research, King Saud University.

\section{REFERENCES}

[1] J. Jiménez, J. Olea, J. Torres, I. Alonso, D. Harder, and K. Fischer, "Biography of Louis Braille and Invention of the Braille Alphabet," Surv. Ophthalmol., vol. 54, no. 1, pp. 142-149, 2009.

[2] E. S.-H. and R. M. Joshi, Handbook of Arabic Literacy, 2014th ed., vol. 9. Dordrecht: Springer Netherlands, 2014.

[3] E. Britan-, "Bleaching $\rightarrow$ Semantic Bleaching Bornu Arabic $\rightarrow$ Subsaharan Arabic,” vol. 1960, pp. 35 - 36, 2003.

[4] Kafeef, “كفيف,” 2018. [Online]. Available: http://www.kafeef.org. [Accessed: 27-Sep-2018].

[5] D. S. Awang Damit, A. I. Che Ani, A. I. Muhamad, M. H. Abbas, and F. Z. Ali, "Dual braille code translator: Basic education tool for visually impaired children," I4CT 2014 - 1st Int. Conf. Comput. Commun. Control Technol. Proc., no. I4ct, pp. 399-402, 2014.

[6] T.-J. Yang, W.-A. Chen, Y.-L. Chu, Z.-X. You, and C.-H. Chou, "Tactile Braille learning system to assist visual impaired users to learn Taiwanese Braille," SIGGRAPH Asia 2017 Posters - SA '17, pp. 1-2, 2017.

[7] H. Nicolau, J. Guerreiro, T. Guerreiro, and L. Carriço, "UbiBraille: designing and evaluating a vibrotactile Braille-reading device," in Proceedings of the 15th International ACM SIGACCESS Conference on Computers and Accessibility, 2013, p. 23.

[8] J. Tang, "Using ontology and RFID to develop a new Chinese Braille learning platform for blind students," Expert Syst. Appl., vol. 40, no. 8, pp. 2817-2827, 2013.

[9] H. Petrie and N. Bevan, The evaluation of accessibility, usability, and user experience, no. June 2009. 2009.

[10] E. Bergman and E. Johnson, "Towards \{Accessible\} \{Human\}\{Computer\} \{Interaction\}," Adv. human-computer Interact., vol. 5, no. 1993, pp. 87-114, 1995.

[11] S. Schmutz, A. Sonderegger, and J. Sauer, "Implementing Recommendations from Web Accessibility Guidelines," Hum. Factors, vol. 58, no. 4, pp. 611-629, 2016.

[12] A. Kavcic, "Software Accessibility: Recommendations and Guidelines," EUROCON 2005 - Int. Conf. Comput. as a Tool"", vol. 2, pp. 10241027, 2005.

[13] R. Lopez, "Matuto, Magbasa, Maglaro: Learning to Read Braille Through Play," 2018.

[14] N. L. C. Gomez et al., "SBK: Smart Braille Keyboard for Learning Braille Literacy in Blind or Visually Impaired People," Proc. 8th Lat. Am. Conf. Human-Computer Interact., no. Figure 1, pp. 26:1--26:4, 2017.

[15] A. Kurniawan, Getting Started with Matlab Simulink and Arduino. PE Press, 2013.

[16] J. Boxall, Arduino workshop: A Hands-On introduction with 65 projects. No Starch Press, 2013.

[17] G. A. Di Lucca, "Testing web-based applications: The state of the art and future trends," Proc. - Int. Comput. Softw. Appl. Conf., vol. 2, no. May, p. 65, 2005.

[18] Paul C. Jorgensen, Software Testing A Craftsman's Approach, vol. 47, no. (2). 2014.

[19] PowerMapper, “One Click Website Testing," 2019. [Online]. Available: https://www.powermapper.com/. [Accessed: 15-Apr-2019]. 
[20] w3c, "Web Content Accessibility Guidelines (WCAG) 2.0. W3.org.," 2019. [Online]. Available: https://www.w3.org/TR/WCAG20/. [Accessed: 15-Apr-2019].

[21] SQUORING, "squoring Providing the best Business Intelligence tool for software and systems projects monitoring," 2019. [Online]. Available: https://www.squoring.com/en/societe/a-propos-de/. [Accessed: 21-Apr2019].
[22] B. Hervé, "Software Qualimetry at Schneider Electric: a field background," pp. 1-10, 2010.

[23] A. Korn, E. Haunschild, B. Kalusche, E. Sax, and M. Gmbh, "HIS AK Softwaretest Inhaltverzeichnis," pp. 1-8, 2008.

[24] G. B. Segura, Densidad de masa ósea en la espondilitis anquilosante, vol. 17 , no. 2. 2001.

[25] Morae, "usability testing with Morae," 2019. [Online]. Available: https://www.techsmith.com/morae.html. [Accessed: 25-Apr-2019]. 